\title{
Pengaruh Popularitas Brand Ambassador NCT 127 terhadap Minat Beli Produk Nu Green Tea
}

\author{
Marsella Aprilia Immaculata, Lusia Savitri Setyo Utami \\ marsella.915170045@stu.untar.ac.id,lusias@fikom.untar.ac.id \\ Fakultas Ilmu Komunikasi Tarumanagara
}

\begin{abstract}
The most popular bottle packaged beverage product in Indonesia is tea. PT ABC President Indonesia produced Nu Green Tea from 2012-present. The marketing technique they used in 2020 is the brand ambassador by partnering with an idol group from South Korea called NCT 127. K-Pop idol group NCT 127 is increasingly accepted in Indonesia with their increasing level of achievement and popularity. The popularity and achievements of NCT 127 have attracted Nu Green Tea's attention to make them their brand ambassadors. This research aims to determine the impact of brand ambassador popularity, NCT 127, on consumer purchase intention towards $\mathrm{Nu}$ Green Tea. The intended consumers in this research are Instagram followers of (@nugreentea.id).The author used the elaboration likelihood model (ELM) as a theoretical reference and marketing communication, brand, brand ambassador, and purchase interest as research concepts. The research method is an explanative survey of 100 respondents as a sample with a questionnaire as the author's instrument. Based on the research results, NCT 127 Brand Ambassador Popularity as variable X significantly affects Consumer Purchase Intention of Nu Green Tea Products as variable Y. NCT 127 popularity as brand ambassador influences consumer interest in buying Nu Green Tea products by $28.2 \%$.
\end{abstract}

Keywords: brand, brand ambassador, consumer purchase intention, $n c t$ 127, nu green tea

\begin{abstract}
Abstrak
Produk minuman kemasan botol yang paling banyak diminati oleh penduduk Indonesia adalah teh. PT ABC President Indonesia memproduksi Nu Green Tea dari tahun 2012-sekarang. Teknik pemasaran yang mereka gunakan di tahun 2020 ini adalah brand ambassador dengan menggandeng idol group dari Korea Selatan bernama NCT 127. Grup idola K-Pop NCT 127 semakin diterima di Indonesia dengan tingkat prestasi dan popularitasnya yang saat ini semakin naik. Popularitas dan prestasi yang dimiliki NCT 127 menarik perhatian Nu Green Tea untuk menjadikan mereka sebagai brand ambassador. Penelitian bertujuan untuk mengetahui pengaruh antara popularitas brand ambassador NCT 127 terhadap minat beli produk $\mathrm{Nu}$ Green Tea oleh konsumen. Konsumen yang dituju oleh penulis dalam penelitian ini adalah pengikut Instagram dari (@nugreentea.id). Penulis menggunakan elaboration likelihood model (ELM) sebagai acuan teori serta marketing communication, brand, brand ambassador, dan minat beli sebagai konsep penelitian. Metode penelitian berupa eksplanatif survei terhadap 100 responden sebagai sampel dengan kuesioner sebagai instrumen penulis. Hasil penelitian, menunjukkan ada pengaruh signifikan variabel Popularitas Brand Ambassador NCT 127 (X) terhadap variabel Minat Beli Produk Nu Green Tea oleh Konsumen (Y). Popularitas brand ambassador NCT 127 memiliki pengaruh terhadap minat beli produk $\mathrm{Nu}$ Green Tea oleh konsumen sebesar 28,2\%.
\end{abstract}

Kata Kunci: brand, brand ambassador, minat beli, nct 127, nu green tea 


\section{Pendahuluan}

Saat ini industri makanan dan minuman di Indonesia menggunakan jasa selebriti sebagai brand ambassador mereka. Kotler dan Armstrong (2018) mendefinisikan brand ambassador sebagai seorang individu maupun kelompok yang menyebarkan informasi sebuah produk ataupun jasa yang dikeluarkan oleh perusahaan yang bersangkutan. Salah satu perusahaan indsutri makanan dan minuman yang juga menggunakan jasa selebriti sebagai brand ambassador mereka adalah PT ABC President Indonesia dengan produknya yang bernama Nu Green Tea. Nu Green Tea merupakan pelopor minuman teh hijau siap saji dalam kemasan botol PET Indonesia. $\mathrm{Nu}$ Green Tea merupakan produk yang pertama kali diproduksi menggunakan teknologi PET Aseptic Filling Technology yang menjamin rasa dan aroma yang unggul, serta produk ready to drink pertama dengan perpaduan teh hijau dan gula batu dalam kemasan botol. Nu Green Tea juga merupakan pemimpin pasar dari PT ABC President Indonesia.

Nu Green Tea sudah diproduksi sejak tahun 2012 hingga 2020 dengan berbagai teknik pemasaran. Salah satunya saat ini dengan menggunakan brand ambassador. Di tahun 2020, Nu Green Tea menggandeng idol group dari Korea Selatan bernama NCT 127 sebagai brand ambassador mereka. Tingkat popularitas grup idola K-Pop di setiap negara diterima secara berbeda-beda termasuk di Indonesia. Seperti halnya grup idola K-Pop NCT 127 yang semakin diterima di Indonesia dengan tingkat prestasi dan popularitasnya yang saat ini semakin naik. Popularitas dan prestasi yang dimiliki NCT 127 menarik perhatian $\mathrm{Nu}$ Green Tea untuk menjadikan mereka sebagai brand ambassador. Greenwood dalam Budiman, Loisa, dan Pandrianto (2018) menyatakan bawha brand ambassador merupakan alat bagi perusahaan untuk menyampaikan informasi dan memikat publik untuk meningkatkan penjualan perusahaan. Oleh karena itu, Nu Green Tea juga berharap dengan NCT 127 sebagai brand ambassador mereka, akan meningkatkan penjualan dan minat beli produk Nu Green Tea.

Berdasarkan latar belakang $d$ atas, rumusan masalah yang penulis angkat ialah apakah terdapat pengaruh antara popularitas brand ambassador NCT 127 terhadap minat beli produk Nu Green Tea oleh konsumen atau tidak. Penelitian ini bertujuan untuk mengetahui ada tidaknya pengaruh antara popularitas brand ambassador NCT 127 terhadap minat beli produk Nu Green Tea oleh konsumen. Oleh karena itu, penulis melakukan penelitian berjudul "Pengaruh Popularitas Brand Ambassador NCT 127 terhadap Minat Beli Produk Nu Green Tea oleh Konsumen”. Penulis menggunakan hipotesa berupa $\mathrm{H}_{0}$ menunjukkan tidak adanya pengaruh antara popularitas brand ambassador NCT 127 dengan minat beli produk Nu Green Tea oleh konsumen. $\mathrm{H}_{1}$ menunjukkan adanya pengaruh antara popularitas brand ambassador NCT 127 dengan minat beli produk Nu Green Tea oleh konsumen.

Dalam melakukan penelitian, penulis menggunakan teori elaboration likelihood model (ELM), konsep marketing communication, konsep brand, konsep brand ambassador, dan konsep minat beli. ELM adalah teori pembentukan dan perubahan sikap akibat komunikasi persuasif (Mowen dan Minor, 2001). Marketing communication adalah segala sesuatu yang dilakukan oleh seluruh perusahaan untuk mempengaruhi persepsi dan perilaku konsumen (Panuju, 2019). Brand adalah tanda, simbol, desain, nama, istilah, atau kombinasi dari itu semua yang menandakan sebuah identitas produk atau jasa perusahaan dan membedakannya dari pesaing lainnya (Keller, 2013). Brand ambassador adalah seorang individu maupun kelompok yang menyebarkan informasi sebuah produk ataupun jasa yang dikeluarkan oleh perusahaan 
yang bersangkutan (Kotler dan Armstrong, 2018). Minat beli merupakan adanya dorongan yang timbul dalam diri seseorang untuk membeli suatu barang ataupun jasa (Arnold, Price, dan Zinkhan, 2011). Penulis menggunakan konsep brand ambassador sebagai acuan untuk dimensi variabel $(\mathrm{X})$ yaitu popularitas brand ambassador NCT 127. Serta teori ELM dan konsep minat beli sebagai acuan untuk dimensi variabel (Y) yaitu minat beli produk $\mathrm{Nu}$ Green Tea oleh konsumen.

\section{Metode Penelitian}

Penulis menggunakan pendekatan kuantitatif dengan metode eksplanasi survei. Eksplanasi survei berarti menjelaskan ada tidaknya hubungan atau pengaruh antara dua variabel dengan menggunakan sampel dan hipotesa (Bungin, 2005). Populasi yang dituju adalah pengikut Instagram@nugreenteaid dengan purposive sampling dan sampel menggunakan rumus Slovin sebanyak 100 sampel (Riyanto dan Hatmawan, 2020). Data primer yang didapatkan berupa hasil pengisian kuisioner dari google form. Data sekunder berupa buku-buku referensi, situs-situs berita online, jurnal, dan penelitian terdahulu baik dalam bentuk fisik maupun digital.

Penulis menggunakan jenis uji validitas bivariate pearson yang bertujuan untuk mengkorelasikan skor dari masing-masing item dengan skor total (Supriadi, 2020). Uji reliabilitas data bertujuan untuk mengukur konsistensi alat ukur yang digunakan dalam penelitian kuantitatif (Budiastuti dan Bandur, 2018). Uji normalitas berfungsi untuk mengetahui bahwa suatu penelitian berdistribusi normal atau tidak (Purwanto, 2019). Analisis regresi sederhana merupakan pengaruh antara dua variabel yang terdiri dari variabel bebas (independen) dan variabel terikat (dependen) yang digunakan untuk membangun persamaan dan membuat perkiraan (Kurniawan, 2009). Uji t digunakan untuk menguji hipotesa (Payadnya dan Jayantika, 2018).

\section{Hasil Temuan dan Diskusi}

Penulis menyebarkan kuisioner melalui google form kepada 100 responden yang terdiri dari 10 pernyataan untuk variabel (X) popularitas brand ambassador NCT 127 dan 9 pernyataan untuk variabel (Y) minat beli produk Nu Green Tea oleh konsumen. Hasil kuisioner dianalisa menggunakan uji validitas bivariate pearson dengan variabel X berkisar 0,565-0,912, variabel Y berkisar 0,542-0,758, dan R tabel sebesar 0,195. Dikarenakan variabel $\mathrm{X}$ dan $\mathrm{Y}$ lebih besar dari pada $\mathrm{R}$ tabel, maka menghasilkan persamaan $\mathrm{R}$ hitung $>\mathrm{R}$ tabel dan butir pernyaan untuk setiap variabel dinyatakn valid (Supriadi, 2020).

Uji reliabilitas dengan cronbach's alpha untuk variabel X adalah 0,94 dan variabel Y adalah 0,85. Dikarenakan nilai cronbach's alpha kedua variabel lebih besar dari 0,70, maka seluruh butir pernyataan dalam kedua variabel dinyatakan reliabel (Budiastuti dan Bandur, 2018). Kemudian data diuji normalitas dengan kolmogrov smirnov test dan didapatkan hasil nilai asymp sig. (2-tailed) sebesar 0,401 yang berarti nilai tersebut lebih besar dari 0,05 . Hal ini dapat disimpulkan bahwa variabel $\mathrm{X}$ dan $\mathrm{Y}$ berdistribusi normal (Purwanto, 2019).

Tabel 1 Uji Normalitas

\begin{tabular}{ccc}
\hline \multicolumn{2}{c}{ Unstandardized Residual } & Keterangan \\
\hline Asymp Sig.(2-tailed) & 0,401 & Data Berdistribusi Normal \\
\hline
\end{tabular}

Sumber: Olah Data Peneliti di SPSS Ver. 20 
Terakhir penulis menggunakan analisa regresi sederhana dan uji t. Analisa regresi sederhana digunakan untuk mencari tahu pengaruh antara variabel bebas (independen) dan variabel terikat (dependen) (Kurniawan, 2009).

Tabel 2 Uji Regresi Sederhana dan Uji T (Coefficientsa)

\begin{tabular}{|l|c|c|c|c|c|}
\hline \multirow{2}{*}{ Model } & \multicolumn{2}{|c|}{$\begin{array}{c}\text { Unstandardized } \\
\text { Coefficients }\end{array}$} & $\begin{array}{c}\text { Standardized } \\
\text { Coefficients }\end{array}$ & \multirow{2}{*}{ Sig. } & \\
\cline { 2 - 5 } & $\mathrm{B}$ & Std. Error & Beta & & \\
\hline (Constant) & 12,031 & 2,736 & & 4,397 & 0,000 \\
1 Popularitas Brand & 0,462 & 0,074 & 0,531 & 6,202 & 0,000 \\
\hline
\end{tabular}

a. Dependent Variable: Minat Beli Produk Nu Green Tea oleh Konsumen Sumber: Olah Data Peneliti di SPSS Ver. 20

Berdasarkan tabel diatas, diketahui nilai Constant (a) sebesar 12.031, sedangkan nilai Popularitas Brand Ambassador NCT 127 (b / koefisien regresi) sebesar 0.462 . Sehingga dapat dituliskan persamaan regresi sebagai berikut:

$$
\begin{gathered}
\mathrm{Y}=\mathrm{a}+\mathrm{bX} \\
\mathrm{Y}=12,031+0,462 \mathrm{X}
\end{gathered}
$$

Konstanta sebesar 12,031 merupakan nilai konsistensi variabel Minat Beli Produk Nu Green Tea oleh Konsumen. Koefisien regresi X sebesar 0,462 menyatakan bahwa setiap penambahan $1 \%$ nilai popularitas brand ambassador NCT 127, maka nilai minat beli produk $\mathrm{Nu}$ Green Tea bertambah sebesar 0,462. Koefisien regresi tersebut bernilai positif, sehingga dapat dikatakan bahwa arah pengaruh variabel $\mathrm{X}$ terhadap Y adalah positif.

Uji t digunakan untuk menguji hipotesa dengan pengambilan keputusan bila $\mathrm{P}-$ Value $>0,05$ maka $\mathrm{H}_{0}$ diterima. Bila $\mathrm{P}-$ Value $<0,05$ maka $\mathrm{H}_{0}$ ditolak. 'Tabel yang digunakan berdasarkan tabel distribusi nilai tabel untuk 100 responden (Purwanto, 2019). Berdasarkan nilai signifikansi dari tabel 2, diperoleh nilai signifikansi sebesar $0,000<0,05$, sehingga dapat disimpulkan bahwa variabel Popularitas Brand Ambassador NCT 127 (X) berpengaruh terhadap variabel Minat Beli Produk Nu Green Tea (Y).

Selain itu, uji t juga dapat dihitung dengan rumus sebagai berikut:

$$
\begin{aligned}
\text { tabel } & =(\mathrm{a} / 2 ; \mathrm{n}-\mathrm{k}-1) \\
& =(0,05 / 2 ; 100) \\
& =(0,025 ; 98) \\
& =1,987
\end{aligned}
$$

Setelah memperoleh data kuesioner responden atas variabel independen dan variabel dependen, dapat disimpulkan bahwa sebagian besar konsumen merasa bahwa popularitas brand ambassador NCT 127 mempengaruhi minat beli produk Nu Green Tea. Mayoritas responden merasa percaya dengan konten dan iklan Nu Green Tea x NCT 127 karena konsumen beranggapan bahwa iklan Nu Green Tea x NCT 127 cocok dan memiliki kesesuaian konsep antara brand ambassador dengan $\mathrm{Nu}$ Green Tea. Selain itu iklan Nu Green Tea x NCT 127 juga dianggap lebih kredibel dan informasi 
yang disampaikan mudah untuk dimengerti. Konsumen cenderung terpengaruh dan memiliki keinginan untuk membeli produk $\mathrm{Nu}$ Green Tea setelah melihat iklan $\mathrm{Nu}$ Green Tea x NCT 127 dengan mencari tahu informasi terkait produk terlebih dahulu sebelum membelinya. Mayoritas responden berada di jalur sentral. Jalur sentral memiliki pengaruh yang lebih besar terhadap minat beli pada penelitian ini dibandingkan dengan jalur periferal.

\section{Kesimpulan}

Popularitas brand ambassador NCT 127 memiliki pengaruh terhadap minat beli produk $\mathrm{Nu}$ Green Tea oleh konsumen. Mayoritas responden merasa percaya dengan konten dan iklan Nu Green Tea x NCT 127 karena konsumen beranggapan bahwa iklan Nu Green Tea x NCT 127 cocok dan memiliki kesesuaian konsep antara brand ambassador dengan Nu Green Tea. Selain itu iklan Nu Green Tea x NCT 127 juga dianggap lebih kredibel dan informasi yang disampaikan mudah untuk dimengerti. Konsumen cenderung terpengaruh dan memiliki keinginan untuk membeli produk $\mathrm{Nu}$ Green Tea setelah melihat iklan Nu Green Tea x NCT 127 dengan mencari tahu informasi terkait produk terlebih dahulu sebelum membelinya. Ini artinya mayoritas konsumen berada di jalur sentral. Jalur sentral memiliki pengaruh yang lebih besar terhadap minat beli pada penelitian ini dibandingkan dengan jalur periferal.

Sehubungan dengan konten Nu Green Tea x NCT 127 yang masih sama selama 11 bulan terakhir, penulis merekomendasikan untuk mengganti foto dan konsep pemotretan dengan melakukan pemotretan dan syuting ulang untuk iklan baru $\mathrm{Nu}$ Green Tea x NCT 127 dengan tujuan agar konten lebih baru dan lebih segar lagi. Selain itu, Nu Green Tea juga dapat berkolaborasi dengan artis atau selebriti lainnya baik dari dalam negeri maupun luar negeri untuk dijadikan brand ambassador-nya. Hal ini bertujuan untuk menarik perhatian dan pangsa pasar dari penggemar selebriti tersebut di luar negeri.

\section{Ucapan Terima Kasih}

Penulisan skripsi ini tidak akan berjalan dengan lancar tanpa bantuan dan dukungan dari banyak pihak. Oleh sebab itu, penulis ingin berterima kasih sebesarsebesarnya kepada semua pihak yang ikut terlibat dan membantu penulis selama proses penelitian ini berlangsung. Penulis juga meminta maaf bila ada salah kata ataupun penulisan dalam pembuatan skripsi dan penelitian ini. Penulis terbuka untuk diberikan kritik dan saran yang nantinya akan penulis jadikan motivasi dan untuk membuat karya ilmiah lebih baik lagi kedepannya serta bermanfaat untuk pada pembaca.

\section{Daftar Pustaka}

Arnold, E., Price, L., \& Zinkhan, G. (2011). Consumers international edition. New York: McGraw-Hill

Budiastuti, D., \& Bandur, A. (2018). Validitas dan reliabilitas penelitian. Jakarta: Mitra Wacana Media

Budiman, V., Loisa, R., \& Pandrianto, N. (2018). Peran brand ambassador pada iklan dalam membangun brand awareness (studi kasus iklan youtube lg $g 7$ thinq bts). Universitas Tarumanagara: Jurnal Komunikasi (Prologia) 
Bungin, H. M. B. (2005). Metodologi penelitian kuantitatif: edisi kedua. Jakarta: Kencana.

Greenwood, G. L. (2013). Fashion marketing communications. United Kingdom: John Wiley \& Sons

Keller, K. L. (2013). Strategic brand management. USA: Prentice Hall.

Kotler, P., \& Armstrong, G. (2018). Principles of marketing. United Kingdom: Pearson.

Kurniawan, A. (2009). Belajar mudah spss untuk pemula. Yogyakarta: MediaKom

Mowen, J. C., \& Minor, M. (2001). Consumer behavior: a framework. United Kingdom: Pearson.

Panuju, R. (2019). Komunikasi pemasaran: pemasaran sebagai gejala komunikasi komunikasi sebagai strategi pemasaran. Jakarta: Prenada Media.

Purwanto. (2019). Analisis korelasi dan regresi linier dengan spss 21. Magelang: StaiaPress.

Riyanto, S., \& Hatmawan, A. A. (2020). Metode riset penelitian kuantitatif penelitian di bidang manajemen, teknik, pendidikan dan eksperimen.

Supriadi, I. (2020). Metode riset akuntansi. Yogyakarta: Deepublish. 